\title{
Early Warning Method and Model of Inland Ship Collision Risk Based on Coordinated Collision-Avoidance Actions
}

\author{
Zhiyou Cheng, ${ }^{1}$ Yaling $\mathrm{Li}^{2,3}$ and Bing Wu $\mathbb{1}^{4}$ \\ ${ }^{1}$ School of Shipping and Naval Architecture, Chongqing Jiaotong University, Chongqing 400074, China \\ ${ }^{2}$ School of Transportation, Wuhan University of Technology, Wuhan 430063, China \\ ${ }^{3}$ School of Economics and Management, Chongqing Jiaotong University, Chongqing 400074, China \\ ${ }^{4}$ National Engineering Research Center for Water Transport Safety (WTSC), Wuhan University of Technology, \\ Wuhan 430063, China \\ Correspondence should be addressed to Bing Wu; 340449024@qq.com
}

Received 20 December 2019; Revised 4 June 2020; Accepted 29 June 2020; Published 20 July 2020

Academic Editor: Richard S. Tay

Copyright ( 92020 Zhiyou Cheng et al. This is an open access article distributed under the Creative Commons Attribution License, which permits unrestricted use, distribution, and reproduction in any medium, provided the original work is properly cited.

To reduce the occurrence of ship collisions, immediate danger, and close-quarters situations in narrow inland waterways, a stepby-step early warning system for ship collision-avoidance actions was developed, along with an early warning method and model of collision risk based on coordinated collision-avoidance actions. This study first analyzed the importance of coordinated collision-avoidance actions in inland waterways, and the process and key components of coordinated collision-avoidance actions were studied. Then, the early warning method of inland ship collision risk based on coordinated collision-avoidance actions was introduced; the effectiveness of the early warning method was comparatively analyzed via experimental observations. A framework of early warning model of inland ship collision risk was created based on the early warning method; a collision risk early warning model for inland ships based on coordinated collision-avoidance actions was proposed according to the relationship between the distance/time to the closest point of approach (DCPA, TCPA), coordination degree of collision-avoidance actions of the two considered ships and collision risk; moreover, the early warning model of inland ship collision risk was further considered for quantitative calculation. Finally, the application of the early warning method and model was demonstrated using a case study. The results indicate that the early warning method of inland ship collision risk based on coordinated collision-avoidance actions could effectively reduce the emergence of close-quarters situations and immediate danger, and the early warning model could quantitatively show the evolution of collision risk of two ships along with the process of coordinated collision-avoidance actions.

\section{Introduction}

Some studies have estimated that $80 \%$ of maritime accidents and $86-95 \%$ of ship collisions are due to human error; thus, the quantification of the impact of human error is of great importance to shipping safety [1]. Additionally, the International Maritime Organization (IMO) conventions [2] and the International Safety Management (ISM) Code [3, 4] have greatly improved shipping safety.

Statistical data show that ship collisions account for the most traffic accidents in inland waterways [5]. An analysis of typical traffic accidents in the inland waterways of the Yangtze River shows that almost all ship collisions are related to human error.
1.1. Relative Research on the Effect of Uncoordinated CollisionAvoidance Actions on Ship-Ship Collision Risk. Guodao [6] believed that all ship-ship collisions are almost caused by the uncoordinated actions of the ships, and this problem needs to be urgently solved. According to Zhao and Wang [7], if the actions of two vessels counteract each other during collision avoidance, so that the vessels fail to pass one another safely, their actions are uncoordinated. Zheng and $\mathrm{Wu}$ [8] studied uncoordinated collision-avoidance actions based on game theory. $\mathrm{Li}$ and $\mathrm{Wu}$ [9] focused primarily on the prevention of uncoordinated collision-avoidance actions. Zhuo and Fang [10] listed the most common types of uncoordinated collision-avoidance actions of two vessels. Zhuo and Hasegawa [11] proposed the use of a trial maneuver 
simulation as a supporting tool in response to uncoordinated collision-avoidance actions of target ships.

1.2. Relative Research on the Evaluation of Ship Collision Risk. Wang and Fan [12] introduced a risk analysis method based on geographic distribution by means of a ship collision modeling and forecasting system. Qu et al. [13] proposed the use of speed dispersion, degree of acceleration and deceleration, and numbers of fuzzy ship domain overlaps to quantitatively assess ship collision risks in the Singapore Strait. Weng et al. [14] estimated vessel collision frequency in the Singapore Strait, which was obtained as the product of the number of vessel conflicts and the causation probability using the real-time vessel movement data from Lloyd's Marine Intelligence Unit (MIU) database, and the conclusions were brought that the container carriers have the highest vessel collision frequency, while Roll-On Roll-Off (RORO) and passenger ships have the lowest frequency; tankers cause the highest head-on collision frequency.

Montewka et al. [15] estimated the risk of ship collision using the minimum distance to collision criterion. Goerlandt and Kujala [16] assessed the reliability and validity of quantitative risk analysis from different perspectives through a case study of ship-ship collision risk by applying different reliability criteria. Goerlandt et al. [17] presented a maritime risk-informed ship collision alert system for realtime operational environments and demonstrated its application. Chen et al. [18] and Wu et al. [19] proposed the composition ship collision risk calculation method based on fuzzy theory. Silveira et al. [20] proposed a method of ship collision risk estimation using the collision diameter based on automatic identification system data. Dong and Frangopol [21] proposed a probabilistic ship collision risk and sustainability assessment, which considers risk attitudes; the probability of ship collision was computed by considering traffic data and operational conditions, and sustainability was quantified considering the detrimental economic, social, and environmental consequences associated with ship collision. Focusing on a human-centered approach, Sotiralis et al. [22] and Wu et al. [23] incorporated human factors into ship collision risk analysis. H. Liu and S. Liu [24] applied gray relational decision-making in the determination of ship collision risk degree. Park et al. [25] proposed the use of trajectory uncertainties to evaluate the probabilistic quantification of ship collision risk. Park and Kim [26] proposed the use of probability flow for the predictive evaluation of ship collision risk. Lin and Yuan [27] proposed a ship collision risk algorithm based on an improved backpropagation neural network. Chen et al. [28] proposed a probabilistic risk analysis for ship-ship collision. Li et al. [29] studied the ship's trajectory planning based on improved multiobjective algorithm for collision avoidance.

1.3. Relative Research on Ship Collision Risk Prediction Based on Distance and Time to the Closest Point of Approach. In ship collision risk early warning systems, the most commonly used methods of risk estimation are the DCPA and TCPA. When DCPA > MinDCPA and TCPA > MinTCPA, there is no risk of collision. When $\mathrm{DCPA} \leq \mathrm{MinDCPA}$ and TCPA $>$ MinTCPA, there is a nonimminent risk of collision. Finally, when DCPA $\leq$ MinDCPA and $0<$ TCPA $\leq$ MinTCPA, there is an imminent risk of collision.

Kearon [30] put forward a method of determining the ship collision risk using weighted DCPA and TCPA via the following equation:

$$
D_{i}=(a T C P A i)^{2}+(b D C P A i)^{2}, \quad i=1,2,3, \ldots n,
$$

where $a$ and $b$ are experimental data obtained statistically, representing weighted values, and $D_{i}$ represents the relative value of ship-ship collision risk.

Zhang [31] proposed and evaluated the effectiveness of a quantitative evaluation model of collision-avoidance decision-making (spatiotemporal evaluation model) in the event of a collision risk by using time and space dimensions and combining the results via the Dempster-Shafer (D-S) evidence theory. The weighted average of two parameters, namely, the distance and DCPA between two ships, was used to measure the spatial gain, and the TCPA between two ships was used to measure the temporal gain. Subsequently, the D-S evidence theory was used to combine the spatial and temporal gain to obtain the result of each decision-making effect at each point in time. Finally, the model's sensitivity and reliability were assessed by changing relevant curves in the model.

Based on the literature review, the relative studies mainly focus on uncoordinated collision-avoidance actions of two ships and evaluation of ship collision risk; minimal work has been reported on early warning of inland ship collision risk based on coordinated ship-ship action.

Regarding anti-collision early warning systems for inland ships, the use of only DCPA and TCPA is not suitable for representing the conditions of inland ship navigation. Therefore, this study developed an early warning method and model of inland ship collision risk based on DCPA, TCPA, and the coordination degree of collision-avoidance actions of two ships.

\section{Early Warning Method of Inland Ship Collision Risk Based on Coordinated Collision-Avoidance Actions}

\subsection{Importance of Coordinated Collision-Avoidance Actions on Inland Ship Collision-Avoidance}

2.1.1. Impact of Coordinated Collision-Avoidance Actions on Inland Ship Collision-Avoidance. Inland waterways are usually relatively narrow, with a high ship density and limited maneuvering space. For two ships to pass each other at a safe distance, collision-avoidance actions of a single ship are often insufficient. Instead, both vessels should implement coordinated anticollision actions to prevent a closequarters situation, an imminent danger, or a collision. If the movements of the two ships are not mutually clear and their intended avoidance strategies and maneuvers are not harmonized, the ship operators might perform conflicting or counteractive avoidance actions. According to Guodao [6], 
all ship collisions are almost caused by the uncoordinated actions of two ships.

The number of inland ship collision accidents caused by the uncoordinated actions of two ships accounted for more than $90 \%$ of the total number of inland ship collision accidents from 2009 to 2015 in the waterway, administrated by the Changjiang Maritime Safety Administration Bureau (Figure 1).

\subsubsection{Collision-Avoidance Rules' Requirements for Coordi- nated Collision-Avoidance Actions of Ships}

(1) International Regulations for Preventing Collisions at Sea. According to Rule 16 of the "International Regulations for Preventing Collisions at Sea, 1972," the provisions of the "action by give-way vessel" stipulate that a vessel directed to give way to another vessel shall, so far as possible, take early and substantial action to keep out of the way. Regarding the "stand-on vessel," Rule 17 stipulates that when one vessel must give way to another, the stand-on vessel should keep her course and speed. The stand-on vessel may, however, take action to avoid collision by her maneuvering alone, as soon as it becomes apparent that the give-way vessel is not taking appropriate action in compliance with the aforementioned rules. When, from any case, the stand-on vessel finds herself so close that collision cannot be avoided by the action of the give-way vessel alone, she shall take such action as will best aid to avoid collision.

(2) Local Collision-Avoidance Rules. Chinese collisionavoidance rules, such as Rule 9 of the "Rules of People's Republic of China for Avoiding Collisions in Inland Waters," stipulate that during collision avoidance, the give-way vessel should take the initiative to keep out of the way of the vessel that was given way in compliance with these rules, whereas the vessel that was given way should pay attention to the actions of the give-way vessel and take appropriate actions to assist the give-way vessel under the given circumstances. When two power-driven vessels meet, their avoidance strategies should be harmonized through sound signals, and the avoidance actions should not be changed [32].

\subsection{Process and Key Components of Coordinated Collision- Avoidance Actions}

\subsubsection{Key Components of Coordinated Collision-Avoidance} Actions. With regard to the input and output factors of a coordinated collision-avoidance process, coordinated collision-avoidance requires that both ships understand each other's movements, unify their collision-avoidance strategies, and take coordinated maneuvering actions throughout the process to ensure safe passage for both ships.

In the present study, 20 sets of avoidance actions were observed on-board inland ships in the Yangtze River of China, which were operated by skilled ship officers with Very High Frequency (VHF), radar and Automatic Identification System (AIS). The observation ships are cargo

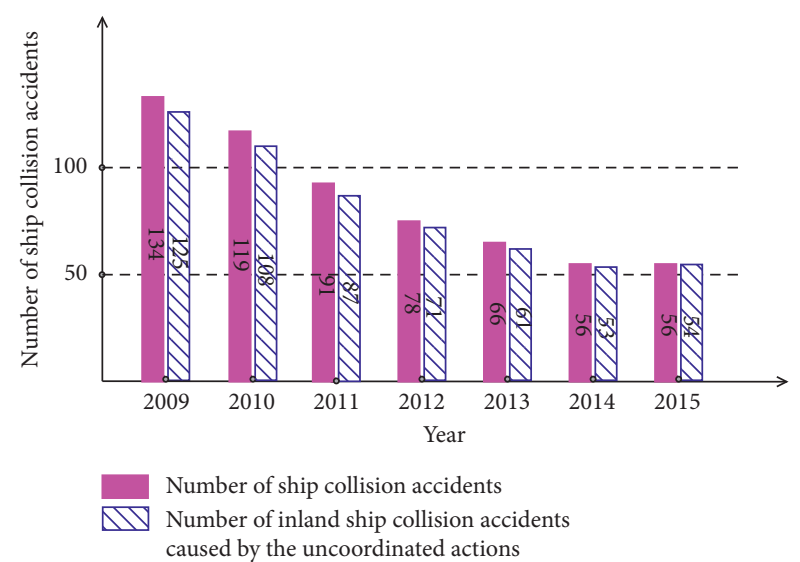

FIgURE 1: Statistics of inland ship collision accidents from 2009 to 2015.

ships; their ship lengths range from 60 to 90 meters, their ship breadths range from 14 to 18 meters, and their ship tonnage ranges from 2000 to 5000 deadweight tons. The target ships are also cargo ships, and their ship lengths range from 50 to 100 meters, their ship breadths range from 14 to 20 meters, and their ship tonnage ranges from 1500 to 6000 tons. The observation process was divided into the following four stages: free navigation, collision risk, close-quarters situation, and immediate danger [32]. During the observation, the coordinated collision-avoidance actions of ship operators were recorded by means of written notes and video recordings.

The observation data showed that during the free navigation stage, the vessel operators took actions in three sets that reflected an understanding of the other vessel's movements. During the collision risk stage, the vessel operators took actions in 15 sets, which reflected an understanding of the other vessel's movements; in 12 sets, the operators took actions showing that their collision-avoidance strategies were uniform; in 10 sets, the operators undertook coordinated maneuvering actions. During the closequarters situation stage, the operators took actions in two sets, which reflected an understanding of the other vessel's movements; in six sets, the operators took actions showing that their collision-avoidance strategies were uniform, and, in four sets, the operators took coordinated maneuvering actions. During the immediate danger stage, there was one set in which the operators were able to avoid collision through coordinated maneuvering actions.

This means that among the 20 sets of observations, the vessel operators in all sets took actions, which reflected an understanding of the other vessel's movements. In 18 sets, the operators took actions that reflected uniform collisionavoidance strategies, and in 15 sets they took coordinated maneuvering actions (Figure 2).

The above-mentioned observation and Figure 2 show that the coordinated collision-avoidance actions of two ships include the following three key elements: understanding each other's movements, unifying collision-avoidance strategies, and taking coordinated maneuvering actions. Understanding each other's movements occurs mainly 


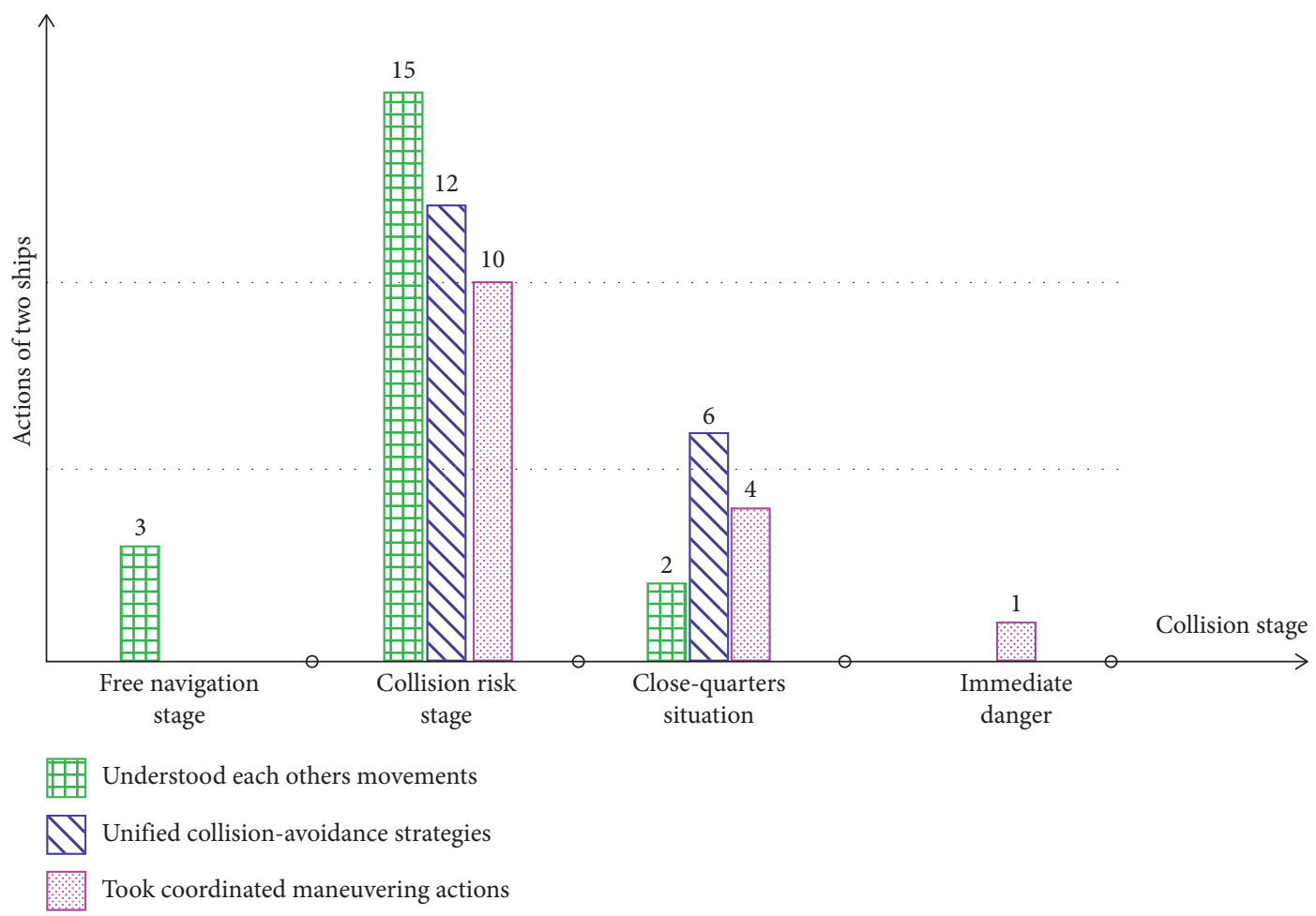

FIgURE 2: Distribution of observed coordinated collision-avoidance actions that two ships typically take in an inland waterway.

during or before the collision risk stage. Unifying the collision-avoidance strategies occurs primarily during the collision risk stage or even during the close-quarters situation stage. Finally, taking coordinated maneuvering actions occurs mainly during the collision risk stage and sometimes during the close-quarters situation and immediate danger stages.

2.2.2. Process of Coordinated Collision-Avoidance Actions. According to the above-mentioned observation analysis and common practice for seafarers, the entire process of coordinated collision-avoidance actions includes five elements, namely, the ships being not in sight of one another, understanding each other's movements, unifying their collision-avoidance strategies, taking coordinated maneuvering actions, and safe passage, as well as four stages, namely, not yet understanding each other's movements, not yet unifying collision-avoidance strategies, not yet taking coordinated maneuvering actions, and verifying the effect of their avoidance actions (Figure 3).

\subsection{Early Warning Method of Inland Ship Collision Risk Based on Coordinated Collision-Avoidance Actions}

\subsubsection{Definition of Coordination Degree of Collision- Avoidance Actions of Two Ships}

(1) Definition of Coordination Degree of Collision-Avoidance Actions of Two Ships. The coordination degree of collisionavoidance actions of two ships was defined to assess the coordination level of collision-avoidance actions of two

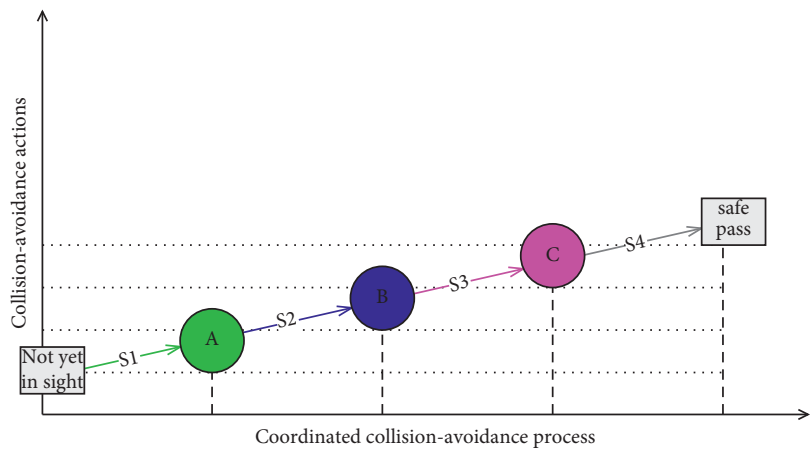

FIGURE 3: Coordinated avoidance process for two ships approaching each other in an inland waterway. A: understanding each other's movements. B: unifying collision-avoidance strategies. C: taking coordinated maneuvering actions. S1: not yet understanding each other's movements. S2: not yet unifying collisionavoidance strategies. S3: not yet taking coordinated maneuvering actions. S4: verifying collision-avoidance effectiveness.

ships during the process of collision avoidance of two ships, including three key components-understanding each other's movements, unifying collision-avoidance strategies, and taking coordinated maneuvering actions. The coordination level of the three key components is from low to high during the process of collision avoidance of two ships (Figure 4).

(2) Quantitative Expression of Coordination Degree of Collision-Avoidance Actions of Two Ships. To develop the early warning method and model of inland ship collision risk based on coordinated collision-avoidance actions, the 


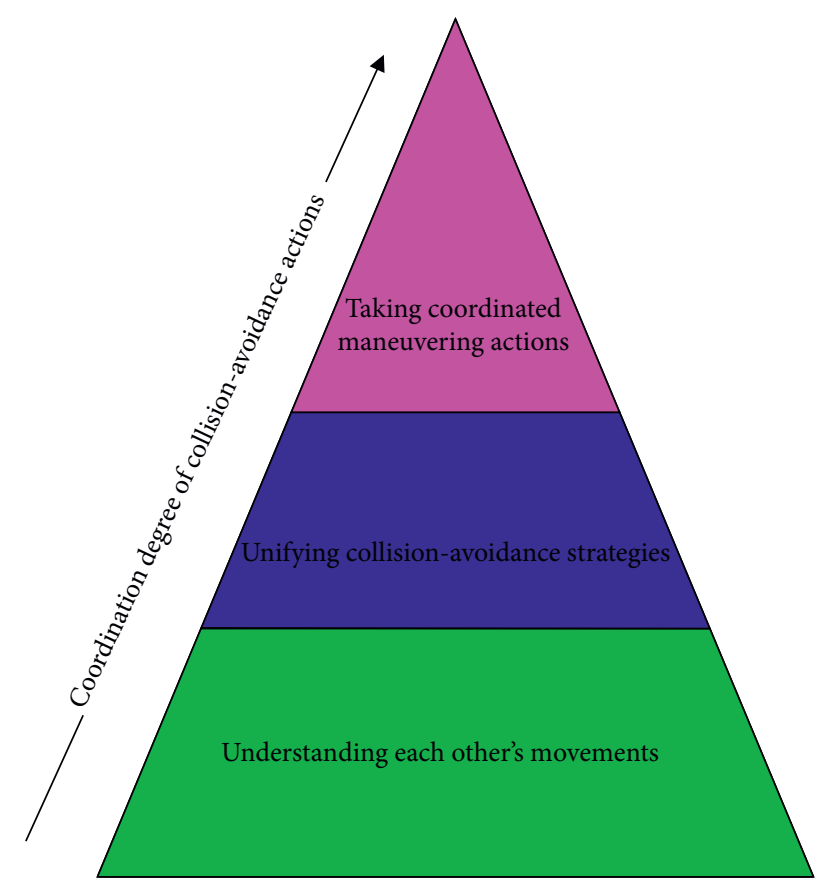

Figure 4: Coordination degree of collision-avoidance actions of two ships.

coordination degree of collision-avoidance actions of two ships was quantified by a dimensionless parameter, $C_{\mathrm{o}}$, with $C_{\mathrm{o}} \in[1, e] ; e$ is a constant, and the value is assigned as 2.71828. The three key elements were assigned the following values: when two ships begin to understand each other's movements, the value of $C_{\mathrm{o}}$ was set to $C_{\mathrm{o} 1}$; when two ships begin to unify their collision-avoidance strategies, the value of $C_{\mathrm{o}}$ was set to $C_{\mathrm{o} 2}$; when two ships begin to take coordinated maneuvering actions, the value of $C_{\mathrm{o}}$ was set to $C_{\mathrm{o} 3}$. Therefore, when two vessels have not yet understood each other's movements, then $C_{\mathrm{o}} \in\left[1, C_{\mathrm{o} 1}\right]$; when the two vessels have understood each other's movements, but their collision-avoidance strategies have not yet been unified, then $C_{\mathrm{o}} \in\left[C_{\mathrm{o} 1}, C_{\mathrm{o} 2}\right]$; when the two vessels have understood each other's movements and unified their collisionavoidance strategies but have not yet taken any coordinated maneuvering actions, then $C_{\mathrm{o}} \in\left[C_{\mathrm{o} 2}, C_{\mathrm{o} 3}\right]$; when the two vessels have understood each other's movements, unified their collision-avoidance strategies, taken coordinated maneuvering actions, and are about to verify the effectiveness of their collision-avoidance actions, then $C_{\mathrm{o}} \in\left[C_{\mathrm{o} 3}\right.$, e]. These parameters, $C_{\mathrm{o} 1}, C_{\mathrm{o} 2}$, and $C_{\mathrm{o} 3}$, have the following relationship: $1<C_{\mathrm{o} 1}<C_{\mathrm{o} 2}<C_{\mathrm{o} 3}<e$.

\subsubsection{Relationship between Opportunity of Taking Coordi-} nated Collision-Avoidance Actions and MinTCPA. When $0 \leq \mathrm{DCPA} \leq \mathrm{MinDCPA}$ (the DCPA safety limit), the sooner two vessels coordinate their collision-avoidance actions, the more the collision imminence can be reduced and the more effective the early warning will be.

Figure 5 shows a comparison of the degree of ship-ship collision imminence under four coordinated collision- avoidance scenarios. In the first scenario, when TCPA > MinTCPA, both vessels have unified their collisionavoidance strategies and prepared to take coordinated maneuvering actions. In the second scenario, when TCPA > MinTCPA, both vessels have understood each other's movements and prepared to unify their collisionavoidance strategies. In the third scenario, when TCPA > MinTCPA, the two vessels are not yet in sight of one another and prepared to understand each other's movements. In the fourth scenario, when TCPA > MinTCPA, the two ships are not yet in sight of one another and have not prepared to take any actions.

It is evident from Figure 5 that in the first scenario, when TCPA $>$ MinTCPA and the two vessels have understood each other's movements and unified their collision-avoidance strategies, alerting both ships to prepare for the coordinated maneuvering action had the greatest early warning effect and ample time for collision avoidance was allowed.

\subsubsection{Early Warning Method of Inland Ship Collision Risk} Based on Coordinated Collision-Avoidance Actions. The ships being not in sight of one another and safe passage, namely, the beginning and end of the entire process of coordinated collision-avoidance actions, had no effect on early warning of inland ship collision risk.

Therefore, the early warning method of the inland ship collision risk based on coordinated collision-avoidance actions was a step-by-step early warning method for ship collision-avoidance actions, along with understanding each other's movements, unifying collision-avoidance strategies, and taking coordinated maneuvering actions. Additionally, when TCPA > MinTCPA and the two vessels have understood each other's movements and unified their collisionavoidance strategies, alerting both ships to prepare for the coordinated maneuvering action had the greatest early warning effect and provided the best chance of avoiding a collision (Figure 6 and Table 1).

\subsection{Comparison of Traditional and New Early Warning} Methods. In this study, a comparative experiment was designed to evaluate the effectiveness of collision risk early warning methods using DCPA, TCPA, and $C_{\mathrm{o}}$. A large-scale navigation simulator (TRANSAS NTPRO 4000) was used. The ship navigation environment was set as a narrow waterway of the Yangtze River of China with high vessel density, and the ship encounter situation was set as a crossing situation. The ownship is a cargo ship with 3000 deadweight tons, the ship length being 92 meters and the ship breadth being 16 meters. The target ships is a cargo ship with 5000 deadweight tons, the ship length being 105 meters and the ship breadth being 16.2 meters. The avoidance actions were operated by a skilled ship officer with VHF, radar and AIS (Figure 7).

A total of 30 effective simulation experiments were carried out, with each experiment divided into two groups, namely, Groups A and B. Group A used DCPA and TCPA to evaluate collision risk, whereas Group B used three 


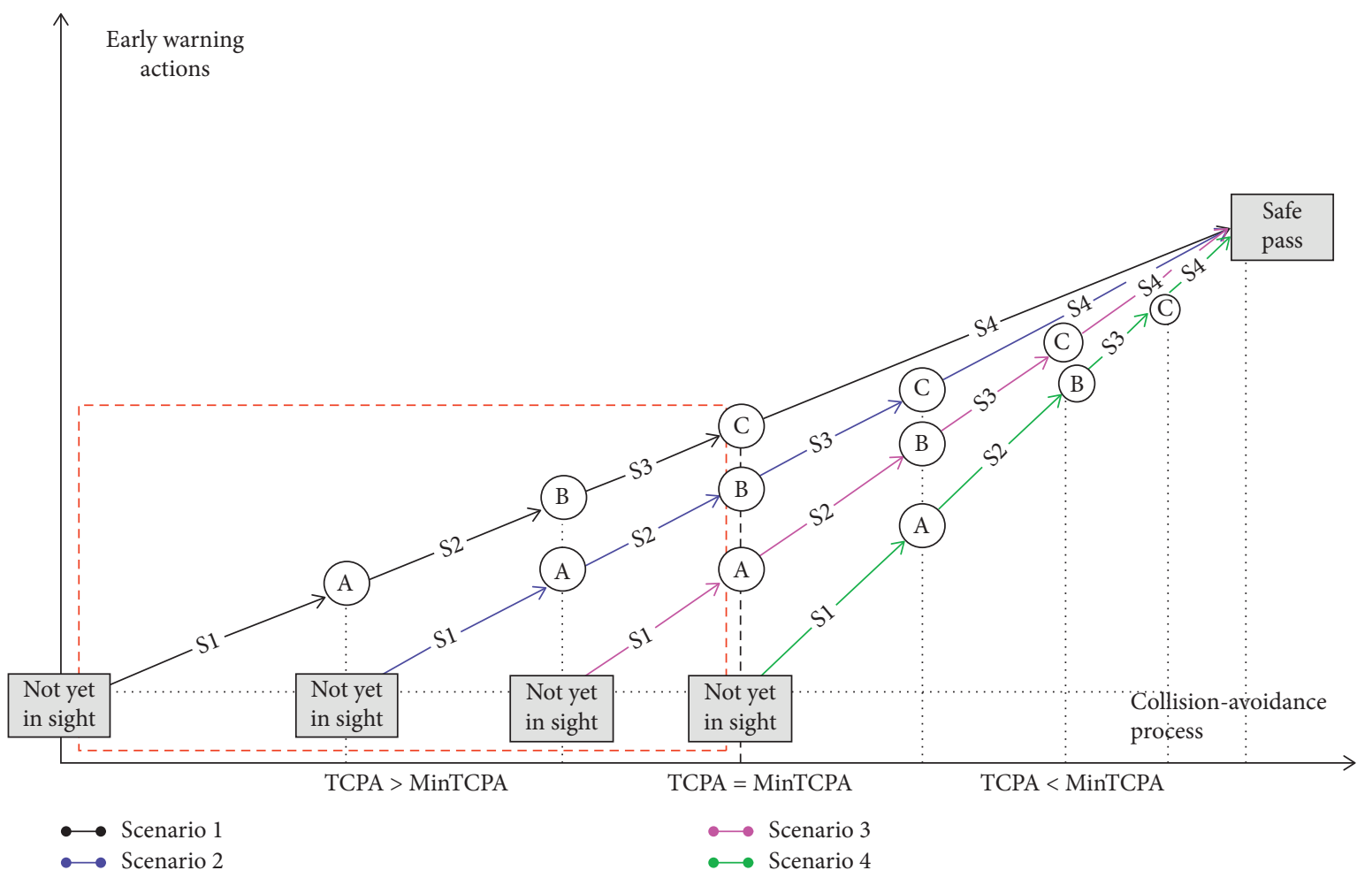

FIGURE 5: Coordinated avoidance actions of two ships with early warning. A: understanding each other's movements. B: unifying collisionavoidance strategies. C: taking coordinated maneuvering actions. S1: not yet understanding each other's movements. S2: not yet unifying collision-avoidance strategies. S3: not yet taking coordinated maneuver's actions. S4: verifying collision-avoidance effectiveness. TCPA: time to the closest point of approach.

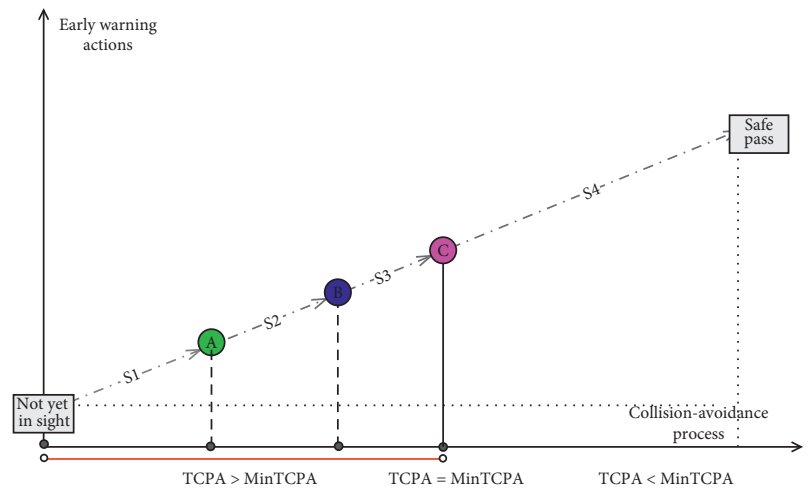

FIGURE 6: Demonstration of early warning method of inland ship collision risk based on coordinated collision-avoidance actions. A: understanding each other's movements. B: unifying collisionavoidance strategies. C: taking coordinated maneuvering actions. S1: not yet understanding each other's movements. S2: not yet unifying collision-avoidance strategies. S3: not yet taking coordinated maneuver's actions. S4: verifying collision-avoidance effectiveness. TCPA: time to the closest point of approach.

parameters, namely, DCPA, TCPA, and $C_{\mathrm{o}}$. The effectiveness of the early warning model in evaluating the collision risk for Groups A and B was compared (Table 2; Figures 8 and 9).

The analysis shows that the use of DCPA, TCPA, and $C_{\mathrm{o}}$ to evaluate collision risk served as an effective step-by-step early warning system. Compared with using only DCPA and TCPA to evaluate collision risk, the use of the three parameters effectively reduced the occurrence of closequarters situations and immediate danger.

\section{Early Warning Model of Inland Ship Collision Risk Based on Coordinated Collision- Avoidance Actions}

3.1. Framework of Early Warning Model of Inland Ship Collision Risk. Based on traditional collision risk estimation via DCPA and TCPA, combined with the important effect of the coordination degree of collision-avoidance actions on inland ship collision avoidance, a framework of the early warning model of inland ship collision risk based on coordinated collision-avoidance actions was established (Figure 10).

\subsection{Early Warning Model of Inland Ship Collision Risk Based} on Coordinated Collision-Avoidance Actions. This study established the model using elementary functions as a result of the complexity of the research question and limited experimental conditions.

3.2.1. Function Format of Early Warning Model. Based on the framework of early warning model of inland ship collision risk, the function format of the early warning model was proposed as follows:

$$
R=f\left(C_{o}, D_{C P A}, T_{C P A}\right),
$$


TABLE 1: Process of early warning method of inland ship collision risk based on coordinated collision-avoidance actions.

\begin{tabular}{|c|c|c|c|}
\hline $\begin{array}{l}\text { Distance to the closest point } \\
\text { of approach (DCPA) }\end{array}$ & $\begin{array}{c}\text { Time to the closest point of } \\
\text { approach (TCPA) }\end{array}$ & $\begin{array}{c}\text { Coordination degree for } \\
\text { collision-avoidance actions } \\
\text { of two ships }\left(C_{\mathrm{o}}\right)\end{array}$ & Early warning conclusion \\
\hline DCPA $>$ MinDCPA & TCPA > MinTCPA & Any value & When $R$ is small, there is no collision risk \\
\hline \multirow{4}{*}{$\mathrm{DCPA} \leq \mathrm{MinDCPA}$} & & $C_{\mathrm{o}} \in\left[1, C_{\mathrm{o} 1}\right]$ & $\begin{array}{l}\text { A collision risk exists, but it is not yet } \\
\text { imminent; an alert is issued that the two ships } \\
\text { have not yet understood each other's } \\
\text { movements }\end{array}$ \\
\hline & TCPA $>$ MinTCPA & $C_{\mathrm{o}} \in\left[C_{\mathrm{o} 1}, C_{\mathrm{o} 2}\right]$ & $\begin{array}{l}\text { A collision risk exists, but it is not yet } \\
\text { imminent; the vessels have understood each } \\
\text { other's movements; an alert is issued that the } \\
\text { vessels have not unified their collision- } \\
\text { avoidance strategies }\end{array}$ \\
\hline & & $C_{\mathrm{o}} \in\left[C_{\mathrm{o} 2}, C_{\mathrm{o} 3}\right]$ & $\begin{array}{c}\text { A collision risk exists, but it is not yet } \\
\text { imminent; the vessels have understood each } \\
\text { other's movements and unified their collision- } \\
\text { avoidance strategies; an alert is issued that the } \\
\text { vessels have not yet taken coordinated } \\
\text { maneuvering actions }\end{array}$ \\
\hline & $0<\mathrm{TCPA} \leq \mathrm{MinTCPA}$ & $C_{\mathrm{o}} \in\left[C_{\mathrm{o} 3}, e\right]$ & $\begin{array}{c}\text { The collision risk is imminent; the vessels have } \\
\text { understood each other's movements, unified } \\
\text { their collision-avoidance strategies, and taken } \\
\text { coordinated maneuvering actions; an alert is } \\
\text { issued that the vessels have to verify the } \\
\text { effectiveness of their collision-avoidance } \\
\text { actions }\end{array}$ \\
\hline
\end{tabular}

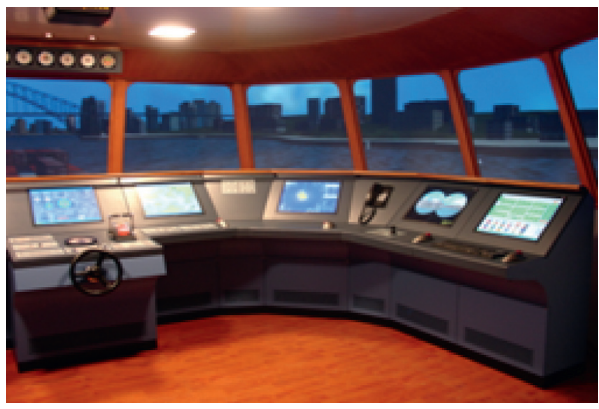

Figure 7: Simulation experiment scenario.

where $R$ represents the risk of ship-ship collision (dimensionless), $\mathrm{R} \in(0,+\infty)$; $C_{\mathrm{o}}$ is the coordination degree of collision-avoidance actions of two ships (dimensionless), $C_{\mathrm{o}} \in[1, \mathrm{e}] ; D_{C P A}$ represents $D C P A, D_{C P A} \in[0,+\infty)$; and $T_{C P A}$ represents TCPA, $T_{C P A} \in[0,+\infty)$.

\subsubsection{Relationships between DCPA, TCPA, $C_{o}$, and Collision Risk}

(1) Relationship between DCPA and Collision Risk. When TCPA reaches a certain value, especially when $0<$ TCPA $\leq$ MinTCPA, the smaller the DCPA value is, the higher the risk of ship-ship collision becomes, even the risk of ship-ship collision increases sharply; when DCPA reaches 0 , the risk of ship-ship collision depends on TCPA and is of a certain value [7]. When TCPA reaches a certain value, especially when $0<\mathrm{TCPA} \leq \mathrm{MinTCPA}$, the higher the DCPA value is, the smaller the risk of ship-ship collision becomes; when DCPA approaches $+\infty$, the risk of ship-ship collision approaches 0 . The comparative experiment from this study also verified the above relationship between DCPA and collision risk (Figure 11).

Based on the above analysis, the elementary functions $y=(a x+b)^{-n} \quad(a>0, b>0, n$ is a natural number $)$ and $y=k^{-c x+d}[k>1, c>0, d \in(-\infty,+\infty)]$ were the closest to expressing the relationship between DCPA and the risk of ship-ship collision.

(2) Relationship between TCPA and Collision Risk. When DCPA reaches a certain value, especially when $0 \leq \mathrm{DCPA} \leq \mathrm{MinDCPA}$, the smaller the TCPA value is, the higher the risk of ship-ship collision becomes, even the risk of ship-ship collision increases sharply; when TCPA reaches 0 , the risk of ship-ship collision depends on DCPA and is of a certain value [7]. When DCPA reaches a certain value, especially when $0 \leq \mathrm{DCPA} \leq \mathrm{MinDCPA}$, the higher the TCPA value is, the smaller the risk of ship-ship collision becomes; when TCPA approaches $+\infty$, the risk of ship-ship collision approaches 0 . The comparative experiment from this study also verified the above relationship between TCPA and collision risk (Figure 12).

Based on the above analysis, the elementary functions $y=(a x+b)^{-n}$ and $y=k^{-c x+d}$ were the closest to expressing the relationship between TCPA and the risk of ship-ship collision.

(3) Relationship between $C_{o}$ and Collision Risk. Based on the good seamanship practice and the information presented in Figure 5, the earlier two ships understand each other's 


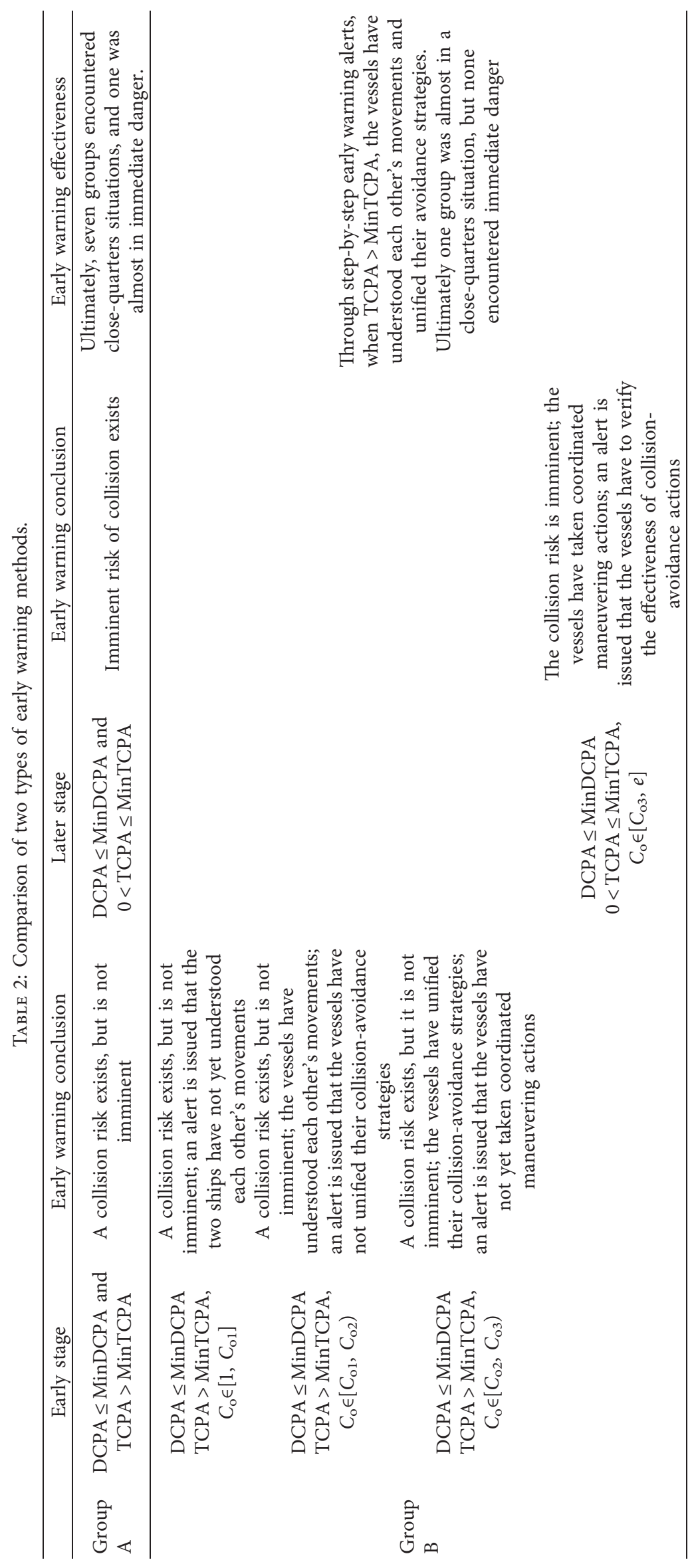




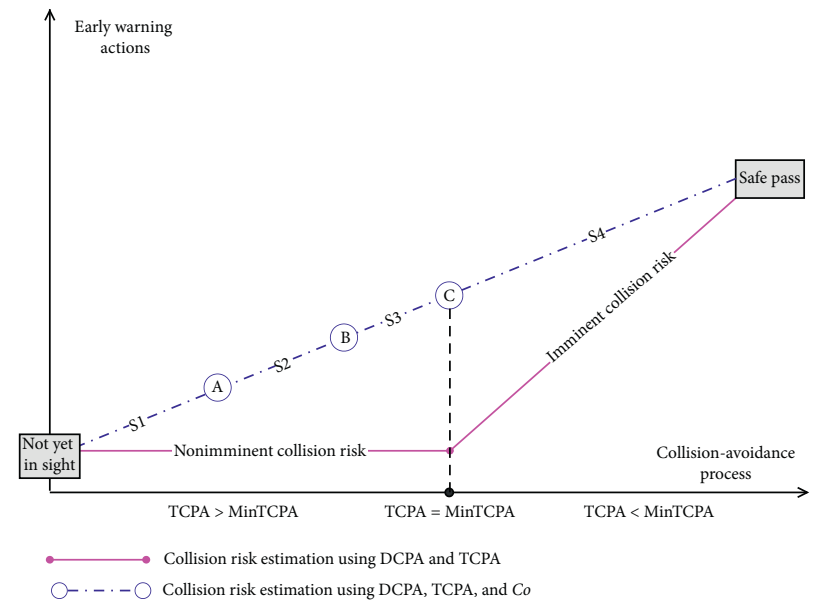

FIGURE 8: Comparison of the early warning process for two ships in an inland waterway proposed in this study. A: understanding each other's movements. B: unifying collision-avoidance strategies. C: taking coordinated maneuvering actions. S1: not yet understanding each other's movements. S2: not yet unifying collision-avoidance strategies. S3: not yet taking coordinated maneuvering actions. S4: verifying collision-avoidance effectiveness. $C_{\mathrm{o}}$ : degree of coordinated collision-avoidance of two ships. DCPA: distance to the closest point of approach; TCPA: time to the closest point of approach.

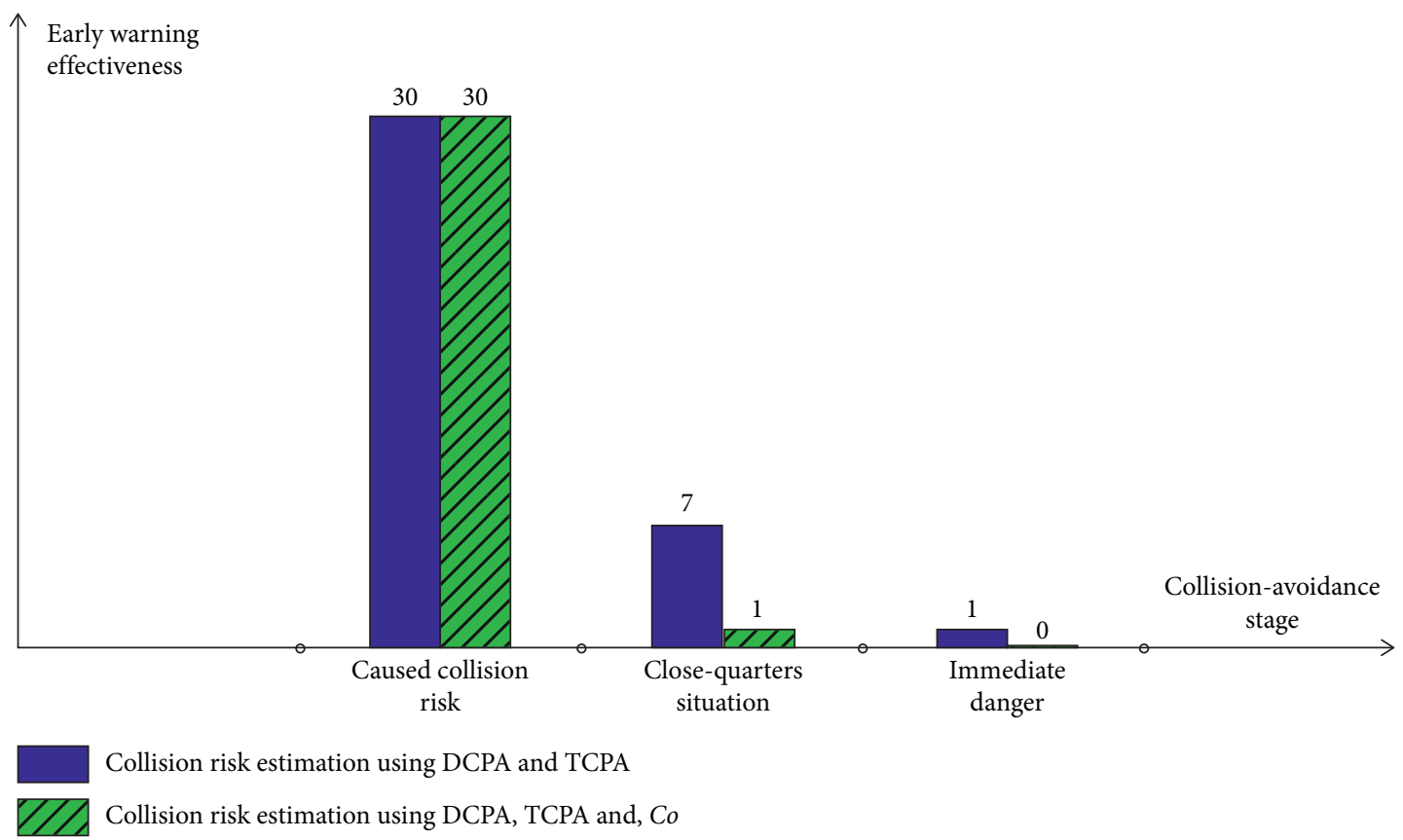

Figure 9: Comparison of the effectiveness of an early warning system for two ships in an inland waterway proposed in this study.

movements, unify their collision-avoidance strategies, and take coordinated maneuvering actions, the higher the coordination degree of collision-avoidance actions is, and the lower the risk of ship-ship collision is. Moreover, when $0 \leq \mathrm{DCPA} \leq$ MinDCPA and TCPA reaches a threshold, the earlier the two vessels take coordinated collision-avoidance actions, the less imminent collision becomes, sharply lowering the chances of collision. The comparative experiment from this study also verified the above relationship between $C_{\mathrm{o}}$ and collision risk (Figure 13).

Based on the above analysis, the elementary functions $y=(a x+b)^{-n}$ and $y=k^{-c x+d}$ were the closest to expressing the relationship between $C_{\mathrm{o}}$ and the risk of ship-ship collision.
(4) Functions of Relationships among DCPA, TCPA, $C_{\mathrm{o}}$, and Collision Risk. Based on the above analysis, the functions of relationships among DCPA, TCPA, $C_{\mathrm{o}}$ and collision risk are summarized in Table 3.

3.2.3. Relationships among DCPA, TCPA, and Co. When DCPA reaches a certain value, especially when $0 \leq \mathrm{DCPA} \leq \mathrm{MinDCPA}$, the smaller the TCPA value is, the more imminent ship-ship collision becomes, the higher is the probability of ship-ship collision. So, the TCPA has the direct impact on the occurrence probability of ship-ship collision. When TCPA reaches a certain value, especially 


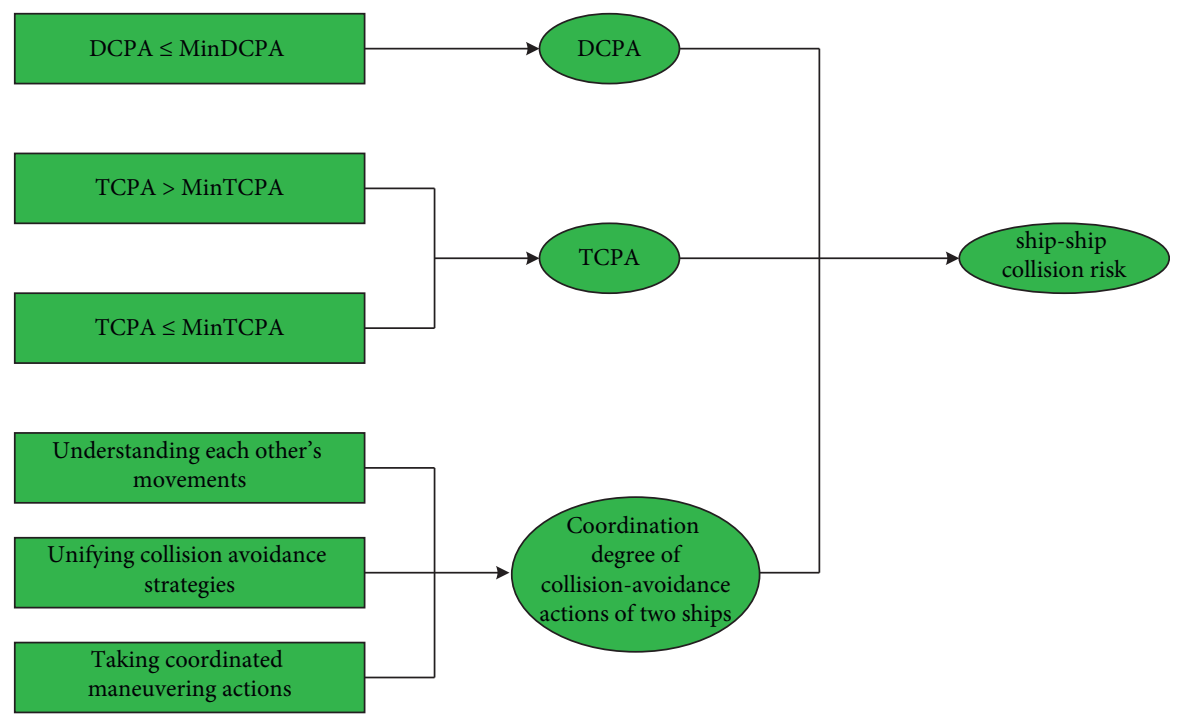

FIGURE 10: Early warning model framework proposed for inland-waterway ships.

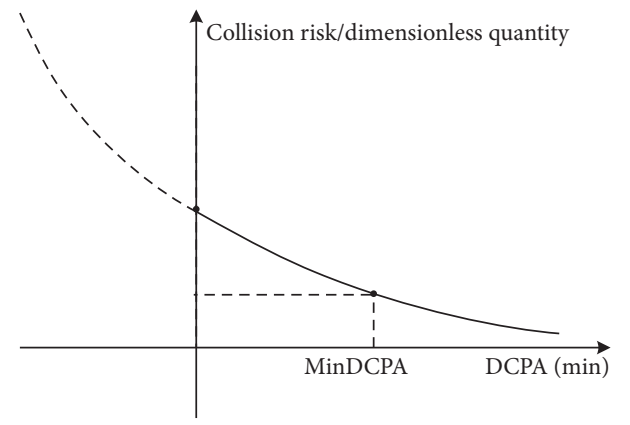

FIGURE 11: Relationship between DCPA and collision risk.

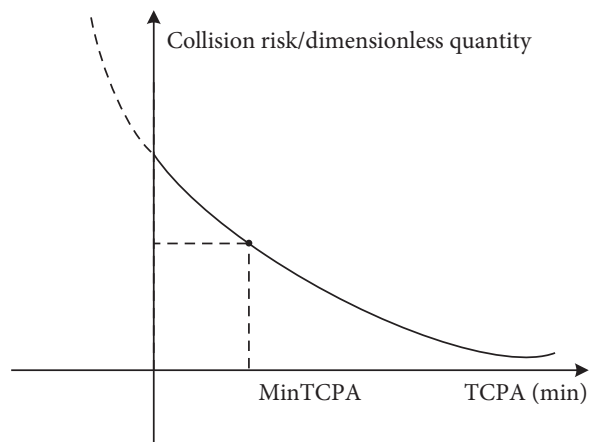

Figure 12: Relationship between TCPA and collision risk.

when $0<\mathrm{TCPA} \leq \mathrm{MinTCPA}$, the smaller the DCPA value is, the higher the hazardous consequence of ship-ship passage is. So, the DCPA has the direct impact on the hazardous consequence of ship-ship passage. According to the general definition of risk, the risk of a dangerous event is the function of the occurrence probability of a dangerous event and the hazardous consequences of the dangerous event $[33,34]$. Therefore, the risk of ship-ship collision is the function of the occurrence probability of a ship-ship collision and the hazardous consequences of a ship-ship passage. Moreover, when $0 \leq \mathrm{DCPA} \leq \mathrm{MinDCPA}, C_{\mathrm{o}}$ has the certain

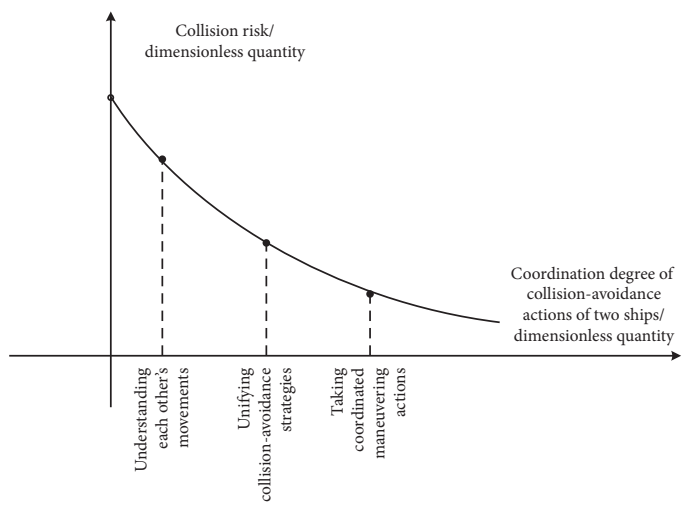

FIGURE 13: Relationship between coordination degree and collision risk of two ships.

impact on the imminent risk of ship-ship collision, namely, has the certain impact on the TCPA of ship-ship collision, has the little impact on the DCPA of ship-ship collision. Based on the above analysis, function (2) was further developed as follows:

$$
R=f_{1}\left(C_{o} T_{C P A}\right) \cdot f_{2}\left(D_{C P A}\right) .
$$

\subsubsection{Early Warning Model for Inland Ship Collision Risk} Based on Coordinated Collision-Avoidance Actions. Based on the above analysis, the closest to expressing the relationships between DCPA, TCPA, $C_{\mathrm{o}}$ and the risk of shipship collision were the following two functions:

$$
\begin{aligned}
R & =\left(\mathrm{a}_{4} D_{C P A}+b_{4}\right)^{-n} k^{-c_{4} C_{o} T_{C P A}+d_{4}} \\
\text { or } R & =\left(a_{5} C_{o} T_{C P A}+b_{5}\right)^{-n} k^{-c_{5} D_{C P A}+d_{5}},
\end{aligned}
$$

where $a_{4}>0 ; a_{5}>0 ; b_{4}>0 ; b_{5}>0 ; c_{4}>0 ; c_{5}>0 ; d_{4} \in(-\infty$, $+\infty)$; and $d_{5} \in(-\infty,+\infty)$.

The impact of TCPA change on the risk of ship-ship collision is faster than the impact of DCPA change, so 
TABLE 3: Functions of relationships between DCPA, TCPA, $C_{\mathrm{o}}$, and collision risk.

\begin{tabular}{lcc}
\hline Relationship* & Proposed function 1 & Proposed function 2 \\
\hline Relationship between DCPA and collision risk & $R=\left(a_{1} D_{C P A}+b_{1}\right)^{-n}$ & $R=k^{-c_{1} D_{C P A}+d_{1}}$ \\
Relationship between TCPA and collision risk & $R=\left(a_{2} T_{C P A}+b_{2}\right)^{-n}$ & $R=k^{-c_{2} T_{C P A}+d_{2}}$ \\
Relationship between $C_{\mathrm{o}}$ and collision risk & $R=\left(a_{3} C_{o}+b_{3}\right)^{-n}$ & $R=k^{-c_{3} C_{o}+d_{3}}$ \\
\hline
\end{tabular}

${ }^{*} a_{1}>0 ; a_{2}>0 ; a_{3}>0 ; b_{1}>0 ; b_{2}>0 ; b_{3}>0 ; c_{1}>0 ; c_{2}>0 ; c_{3}>0 ; d_{1} \in(-\infty,+\infty) ; d_{2} \in(-\infty,+\infty) ; d_{3} \in(-\infty,+\infty)$.

function (4) is the closest to expressing the relationship between DCPA, TCPA, $C_{\mathrm{o}}$ and the risk of ship-ship collision in elementary functions. Based on function (4), the early warning model for inland ship collision risk based on coordinated collision-avoidance actions was proposed as follows:

$$
R=\frac{1}{\left(a C_{o} T_{C P A}+b\right)^{n} k^{c D_{C P A}-d}},
$$

where $a>0 ; b>0 ; c>0 ; d \in(-\infty,+\infty) ; k>1$; and $n$ is a natural number.

\subsection{Further Study of Early Warning Model of Inland Ship Collision Risk}

3.3.1. Further Simplification of Early Warning Model. Function (5) is further simplified to evaluate the value of model. $R$, the risk of ship-ship collision, is normalized, and $R \in(0,1]$. When DCPA $=0$ and TCPA $=0$, regardless of the $C_{\mathrm{o}}$ values, the ship-ship approaches to collide, and $R=1$. When TCPA = MinTCPA, $R$ depends on DCPA and $C_{0}$. When DCPA $=$ MinDCPA, $R$ depends on TCPA and $C_{\mathrm{o}}$. When DCPA $=$ MinDCPA, TCPA $=$ MinTCPA, $R$ depends on $C_{\mathrm{o}}$. The constants, $a$ and $c$, are replaced by MinTCPA and MinDCPA. So, function (5) was further developed as follows:

$$
R=\frac{1}{\left(\left(C_{o} T_{C P A} / \operatorname{Min} T_{C P A}\right)+k^{d / n}\right)^{n} k^{\left(D_{C P A} / M i n D_{C P A}\right)-d}},
$$

where $R \in(0,+1]$; $\operatorname{Min} T_{C P A}$ is the TCPA safety limit, its value depends on the given environment and condition, such as ship dimensions, visibility, water state, and $\operatorname{Min} T_{C P A} \in[0$, $+\infty$ ); $\operatorname{MinD}_{\mathrm{CPA}}$ is the DCPA safety limit, its value depends on the given environment and condition, such as ship dimensions, visibility, water state, and $\operatorname{MinD}_{\mathrm{CPA}} \in[0,+\infty)$; $d$ is a constant, $d \in(-\infty,+\infty)$; and $n$ is a natural number.

\subsubsection{Verification of Model Applicability}

(1) Verification of the Relationships between DCPA, TCPA, $C_{o}$, and Collision Risk. When $0 \leq \mathrm{DCPA} \leq \mathrm{MinDCPA}$, and it reaches a certain value, $R$ mainly depends on the TCPA value; the higher the TCPA value is, the lower the $R$ value becomes, and the lower the TCPA value is, the higher the $R$ value becomes. When $0 \leq \mathrm{TCPA} \leq \mathrm{MinTCPA}$, and it reaches a certain value, $R$ mainly depends on the DCPA value; the higher the DCPA value is, the lower the $R$ value becomes, and the lower the DCPA value is, the higher the $R$ value becomes. When $0 \leq \mathrm{DCPA} \leq \mathrm{MinDCPA}$ and it reaches a set value, and when $0<$ TCPA $\leq$ MinTCPA and it reaches a set value, the higher the $C_{\mathrm{o}}$ value is, the lower the $R$ value becomes, and the lower the $C_{\mathrm{o}}$ value is, the higher the $R$ value becomes.

Function (6) can reflect the above relationships between DCPA, TCPA, $C_{\mathrm{o}}$ and collision risk.

(2) Verification of Value Range of $R$. When DCPA $=0$ and TCPA $=0, R=1$. When DCPA approaches $+\infty$, regardless of the TCPA and $C_{\mathrm{o}}$ values, $R$ approaches 0 . When TCPA approaches $+\infty$, regardless of the DCPA and $C_{\mathrm{o}}$ values, $R$ approaches 0.

Function (6) is compatible with the aforementioned value range of $R$.

\section{Case Study}

The Niukou waterway of the upper Yangtze River with high vessel density was selected as a case study. The visibility and water state are good. Ship A's length was 106 meters, and its breadth was 16 meters, navigated along the narrow waterway; ship B's length was 92 meters, and its breadth was 16 meters, crossed the waterway so that the two ships were at a collision risk, and DCPA $=0.1$ nmile (Figure 14).

According to the actual environment and professional experiences, it was assumed that MinDCPA $=0.3$ nmile, MinTCPA $=12 \mathrm{~min}, n=1, k=2.71828$, and $d=1$. The $R$ values in various stages were calculated as described below.

In stage one (S1), TCPA $>18$ min and DCPA $=0.1$ nmile, the collision risk is detected but is not imminent, and the two vessels have not yet understood each other's movements, $C_{\mathrm{o}}=1 \in[1,1.2]$. According to function (6), $R<0.4618$, and a warning is issued that the vessels should begin to understand each other's movements.

On the first key point of coordinated collision-avoidance actions (A), TCPA $=18 \mathrm{~min}$ and DCPA $=0.1 \mathrm{nmile}$; the two vessels begin to understand each other's movements, $C_{\mathrm{o}}=1.2$. According to function (6), $R=0.4311$.

In stage two (S2), $15 \mathrm{~min}<\mathrm{TCPA}<18 \mathrm{~min}$ and DCPA $=0.1$ nmile, the collision risk is detected but is not imminent, and the two vessels have understood each other's movements but have not unified their collision-avoidance strategies, $C_{\mathrm{o}}=1.2 \in[1.2,1.5]$. According to function (6), $0.4311<R<0.4618$, and a warning is issued that the two vessels should unify their collision-avoidance strategies.

On the second key point of coordinated collisionavoidance actions (B), TCPA $=15 \mathrm{~min}$ and $\mathrm{DCPA}=0.1$ nmile; the two vessels begin to unify their collision-avoidance strategies, $C_{\mathrm{o}}=1.5$. According to function (6), $R=0.4241$.

In stage three (S3), $12 \mathrm{~min}<\mathrm{TCPA}<15 \mathrm{~min}$ and $\mathrm{DCPA}=0.1$ nmile, the collision risk is detected but is not imminent, and the two vessels have unified their collision- 


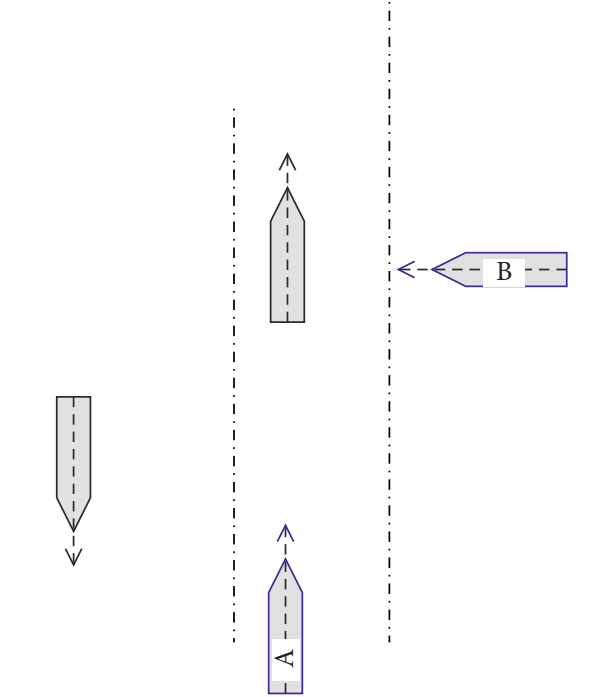

Stage 1

(a)

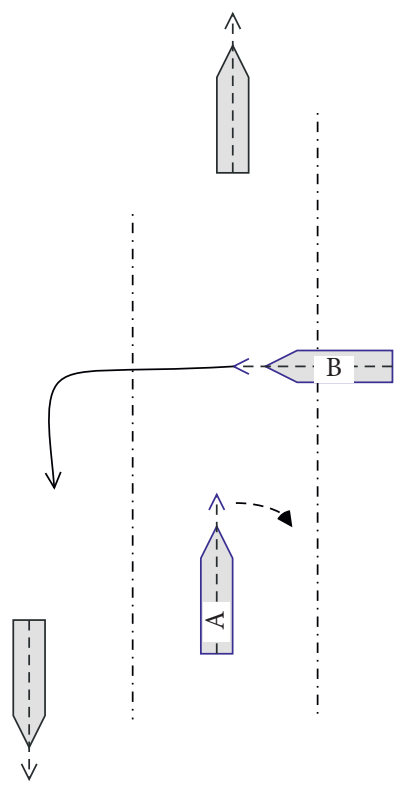

Stage 3

(c)

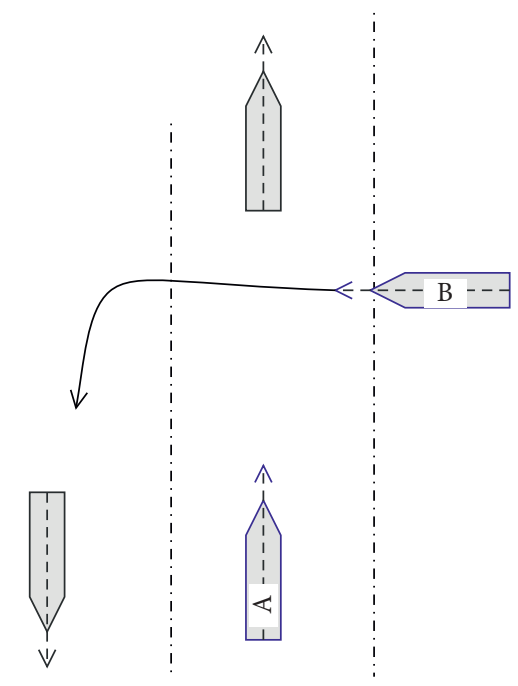

Stage 2

(b)

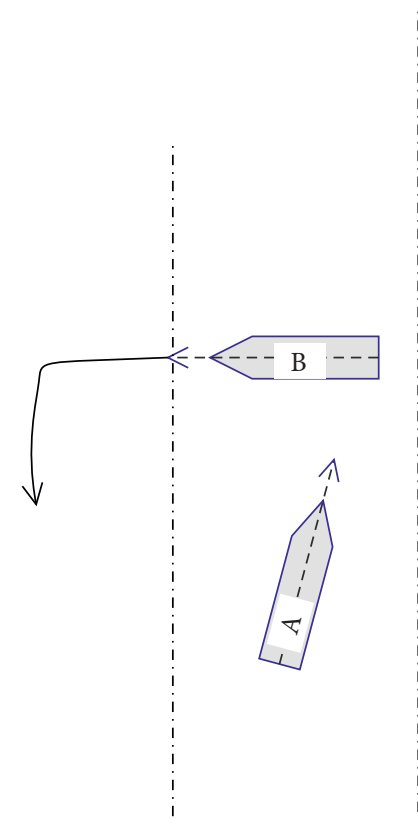

Stage 4

(d)

FIGURE 14: Stages of collision-avoidance in a narrow waterway of the Yangtze River. Stage one: the two vessels have not yet understood each other's movements. Stage two: the vessels have not yet unified their collision-avoidance strategies. Stage three: the vessels have not yet taken coordinated maneuvering actions. Stage four: the vessels have to verify collision-avoidance effectiveness.

avoidance strategies, but have not taken coordinated maneuvering actions, $C_{\mathrm{o}}=1.5 \in[1.5,2]$. According to function (6), $0.4241<R<0.4618$, and a warning is issued that the two vessels should take coordinated maneuvering actions.

On the third key point of coordinated collision-avoidance actions $(\mathrm{C}), \mathrm{TCPA}=12 \mathrm{~min}$, the two vessels begin to take coordinated maneuvering actions, and the DCPA becomes 0.3 nmile, $C_{\mathrm{o}}=2$. According to function (6), $R=0.2119$.
In stage four (S4), $0 \mathrm{~min}<\mathrm{TCPA}<12 \mathrm{~min}$, the two vessels have taken coordinated maneuvering actions, and the DCPA becomes 0.3 nmile (actually DCPA $\geq 0.3$ nmile), $C_{\mathrm{o}}=2 \in[2$, 2.71828). According to function (6), $0.2119<R<0.3678$.

Through these stepwise early warning alerts based on the proposed method and model, ships A and B achieved coordinated collision avoidance, with ample time to take appropriate actions (Figure 15). 


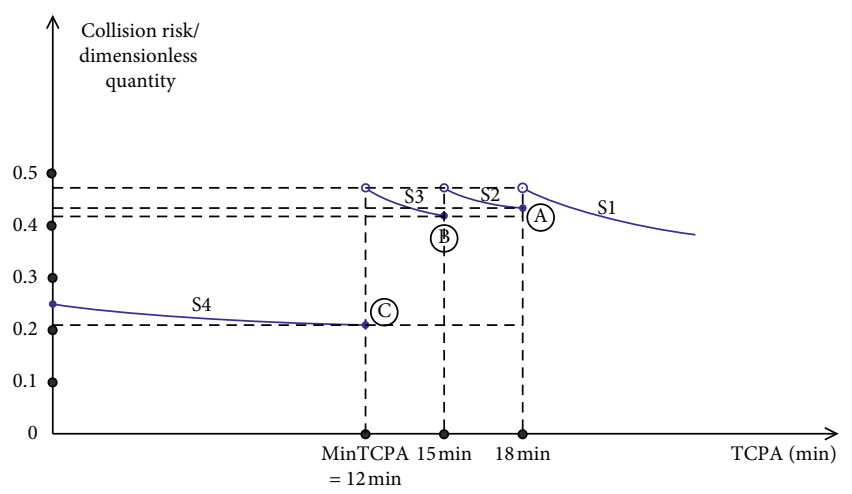

FIGURE 15: Distribution of early warning and risk estimation of ship-ship collision. A: understanding each other's movements. B: unifying collision-avoidance strategies. C: taking coordinated maneuvering actions. S1: not yet understanding each other's movements. S2: not yet unifying collision-avoidance strategies. S3: not yet taking coordinated maneuvering actions. S4: verifying collision-avoidance effectiveness. TCPA: time to the closest point of approach.

\section{Discussion}

Compared with traditional collision risk evaluation methods based on DCPA and TCPA, the proposed early warning method and model of ship collision risk based on coordinated collision-avoidance actions serve as a step-by-step early warning system that allows ample time for taking appropriate collision-avoidance actions. However, this early warning method and model of ship-ship collision risk for inland waterways based on coordinated collision-avoidance actions has the following shortcomings: (a) the early warning method could not be used without effective communication between two ships; (b) the early warning model only uses elementary functions to model the ship-ship collision risk, the prediction accuracy of the model is insufficient, and the prediction accuracy of the model could be enhanced using senior functions; (c) the simplification from function (5) to function (6) partly limits the values of the random factors such as a, $b$, and $c$, although $d$ can represent random factors without limitation in function (6); (d) there are not enough experimental data in the study as a result of limited research conditions, and more experimental data are needed to prove the effectiveness of the early warning method and model.

\section{Conclusions}

Modeling DCPA, TCPA, and $C_{\mathrm{o}}$ to estimate ship-ship collision risk serves as a step-by-step early warning system. Compared with traditional collision risk estimation based only on DCPA and TCPA, the early warning method of inland ship collision risk based on DCPA, TCPA, and $C_{\mathrm{o}}$ could effectively reduce the emergence of close-quarters situations and immediate danger. The early warning model could quantitatively show the evolution of collision risk of two ships along with a process of coordinated collisionavoidance actions. When $0 \leq \mathrm{DCPA} \leq \mathrm{MinDCPA}$ and
TCPA > MinTCPA, the two vessels have understood each other's movements and unified their collision-avoidance strategies, and an alert has been issued that the vessels should take coordinated maneuvering actions; ample time for collision avoidance is allowed and the effectiveness of the early warning system is enhanced.

\section{Data Availability}

The data used in this study are available from the corresponding author upon request.

\section{Conflicts of Interest}

The authors declare that they have no conflicts of interest regarding the publication of this paper.

\section{Acknowledgments}

This work was supported by the China Postdoctoral Science Foundation (Grant no. 2016M592889XB), the Science and Technology Research Program of the Chongqing Education Commission (Grant no. KJ1500519), and the Hubei Provincial Key Laboratory of Inland Navigation Technology (Grant no. NHHY2015001).

\section{References}

[1] S. Li, Q. Meng, and X. Qu, "An overview of maritime waterway quantitative risk assessment models," Risk Analysis, vol. 32, no. 3, pp. 496-512, 2012.

[2] O. F. Knudsen and B. Hassler, "IMO legislation and its implementation: accident risk, vessel deficiencies and national administrative practices," Marine Policy, vol. 35, no. 2, pp. 201-207, 2011.

[3] E. Tzannatos and D. Kokotos, "Analysis of accidents in Greek shipping during the pre- and post-ISM period," Marine Policy, vol. 33, no. 4, pp. 679-684, 2009.

[4] D. Kokotos and D. Linardatos, "An application of Data mining tools for the study of shipping safety in restricted waters," Safety Science, vol. 49, no. 2, pp. 192-197, 2010.

[5] N. Wu, "Fully understanding some characteristics of inland river ship collision accidents," Navigation of China, vol. 33, pp. 79-84, 2010.

[6] Z. Guodao, "On collision accidents and ship operator judgement," Safety on Sea (Japan), vol. 10, pp. 14-21, 1989.

[7] J. Zhao and F. Wang, The Principles of Ship Collision Avoidance, Dalian Maritime University Press, Dalian, China, 1999.

[8] Z. Zheng and Z. Wu, Collision Avoidance Decision-Making, Dalian Maritime University Press, Dalian, China, 2000.

[9] J. Li and X. Wu, "Reducing the non-coordination collision: prevent action with the application of AIS," World Shipping, vol. 27, pp. 9-10, 2004.

[10] Y. Zhuo and X. Fang, "Trial maneuver countermeasure method for uncoordinated ship-ship collision avoidance action," Ship Safety Management Proceedings, vol. 6, pp. 158161, 2010.

[11] Y. Zhuo and K. Hasegawa, "Ship override control for uncoordinated anti-collision action using trial manoeuvre," IFAC Proceedings Volumes, vol. 46, no. 33, pp. 108-113, 2013.

[12] J. Wang and Y. Fan, "Risk analysis based on the ship collision modeling and forecasting system," in Proceedings of the IEEE 
International Conference on Systems, Man and Cybernetics, pp. 12-15, Singapore, October 2008.

[13] X. Qu, Q. Meng, and L. Suyi, "Ship collision risk assessment for the Singapore Strait," Accident Analysis \& Prevention, vol. 43, no. 6, pp. 2030-2036, 2011.

[14] J. Weng, Q. Meng, and X. Qu, "Vessel collision frequency estimation in the Singapore Strait," Journal of Navigation, vol. 65, no. 2, pp. 207-221, 2012.

[15] J. Montewka, F. Goerlandt, and P. Kujala, "Determination of collision criteria and causation factors appropriate to a model for estimating the probability of maritime accidents," Ocean Engineering, vol. 40, pp. 50-61, 2012.

[16] F. Goerlandt and P. Kujala, "On the reliability and validity of ship-ship collision risk analysis in light of different perspectives on risk," Safety Science, vol. 62, pp. 348-365, 2014.

[17] F. Goerlandt, J. Montewka, V. Kuzmin, and P. Kujala, "A riskinformed ship collision alert system: framework and application,” Safety Science, vol. 77, pp. 182-204, 2015.

[18] S. Chen, R. Ahmad, B.-G. Lee, and D. Kim, "Composition ship collision risk based on fuzzy theory," Journal of Central South University, vol. 21, no. 11, pp. 4296-4302, 2014.

[19] B. Wu, T. Cheng, T. L. Yip, and Y. Wang, "Fuzzy logic based dynamic decision-making system for intelligent navigation strategy within inland traffic separation schemes," Ocean Engineering, vol. 197, p. 106909, 2020.

[20] P. Silveira, A. P. Teixeira, and C. Guedes Soares, "Assessment of ship collision estimation methods using AIS data," in Maritime Technology and Engineering, C. Guedes Soares and T. A. Santon, Eds., pp. 195-204, CRC Press, Lison, France, 2015.

[21] Y. Dong and D. M. Frangopol, "Probabilistic ship collision risk and sustainability assessment considering risk attitudes," Structural Safety, vol. 53, pp. 75-84, 2015.

[22] P. Sotiralis, N. P. Ventikos, R. Hamann, P. Golyshev, and A. P. Teixeira, "Incorporation of human factors into ship collision risk models focusing on human centred design aspects," Reliability Engineering \& System Safety, vol. 156, pp. 210-227, 2016.

[23] B. Wu, X. Yan, Y. Wang, and C. G. Soares, "An evidential reasoning-based CREAM to human reliability analysis in maritime accident process," Risk Analysis, vol. 37, no. 10, pp. 1936-1957, 2017.

[24] H. Liu and S. Liu, "Application of grey relational decisionmaking on determination of ship collision risk degree," Revista Técnica de la Facultad de Ingeniería Universidad del Zulia, vol. 39, pp. 359-365, 2016.

[25] J. Park, J. Han, J. Kim, and N.-S. Son, "Probabilistic quantification of ship collision risk considering trajectory uncertainties," IFAC-PapersOnLine, vol. 49, no. 23, pp. 109-114, 2016.

[26] J. Park and J. Kim, "Predictive evaluation of ship collision risk using the concept of probability flow," IEEE Journal of Oceanic Engineering, vol. 42, no. 4, pp. 836-845, 2017.

[27] X. G. Lin and Y. Q. Yuan, "Algorithm of ship collision risk based on improved BP neural network," in Proceedings of the IEEE International Conference on Mechatronics and Automation, pp. 5-8, Changchun, China, August 2018.

[28] P. Chen, Y. Huang, J. Mou, and P. H. A. J. M. van Gelder, "Probabilistic risk analysis for ship-ship collision: state-ofthe-art," Safety Science, vol. 117, pp. 108-122, 2019.

[29] J. Li, H. Wang, W. Zhao, and Y. Xue, "Ship's trajectory planning based on improved multiobjective algorithm for collision avoidance," Journal of Advanced Transportation, vol. 2019, Article ID 4068783, 12 pages, 2019.
[30] J. Kearon, Computer Programs for Collision Avoidance and Traffic Keeping, Academic Press, London, UK, 1997.

[31] J. Zhang, Study on Ship Collision Risk Assessment and Anticollision Decision Making Methodology, Wuhan University of Technology, Wuhan, China, 2013.

[32] J. Ding, Ship Collision Avoidance and Signalling, Dalian Maritime University Press, Dalian, China, 2006.

[33] M. Rausand, Risk Assessment: Theory, Methods, and Applications, Wiley Press, Hoboken, NJ, USA, 2011.

[34] B. Wu, T. L. Yip, X. Yan, and C. Guedes Soares, "Fuzzy logic based approach for ship-bridge collision alert system," Ocean Engineering, vol. 187, Article ID 106152, 2019. 